Running Head: MATERNAL STRESS AND FLUOXETINE EXPOSURE

\title{
Behavioural outcomes of adult female offspring following maternal stress and perinatal fluoxetine exposure.
}

\author{
Veronika Kiryanova $^{1,3,4}$, Sara J. Meunier ${ }^{1,3}$, Richard H. Dyck ${ }^{1,2,3,4}$
}

Departments of ${ }^{1}$ Psychology, ${ }^{2}$ Cell Biology and Anatomy, ${ }^{3}$ Hotchkiss Brain Institute, ${ }^{4}$ Alberta Children's Hospital Research Institute, University of Calgary, Calgary, Alberta, Canada

Corresponding author:

Richard H. Dyck, PhD, Professor, Department of Psychology, The University of Calgary 2500 University Drive, NW Calgary, AB Canada T2N 1N4

Email: rdyck@ucalgary.ca

(403) 220-4206 (office)

(403) 220-5093 (lab)

(403) 282-8249 (fax)

Acknowledgement of Funding: This work was supported by NSERC Discovery and CIHR Operating grants to RHD, an NSERC and AIHS graduate scholarship to VK and a CIHR summer studentship to SM.

Competing Interests: The authors declare that no competing interests exist. The authors have full control of all primary data and agree to allow the journal to review their data if requested 


\begin{abstract}
Depression, anxiety, and stress are common in pregnant women. One of the primary pharmacological treatments for anxiety and depression is the antidepressant fluoxetine (Flx). Maternal stress, depression, and Flx exposure are known to effect neurodevelopment of the offspring, however, their combined effects have been scarcely studied, especially in female offspring. The present study investigated the combined effects of maternal stress during pregnancy and perinatal exposure to Flx on the behaviour of female mice as adults. METHODS: Mouse dams were exposed to either chronic unpredictable stress (embryonic (E) day 7 to E18), or FLX (E15- postnatal day 12), or a combination of stress and FLX or left untreated. At two months of age, the female offspring went through a comprehensive behavioural test battery. RESULTS: Maternal stress led to increased activity and alterations of prepulse inhibition in the adult female offspring. Maternal treatment with Flx had a potentially beneficial effect on spatial memory. The combination of prenatal stress and perinatal Flx exposure did not interact in their effects. These results suggest that gestational Flx exposure may have a limited negative impact on female offspring.
\end{abstract}

Keywords:

SSRI; fluoxetine; prenatal stress; development; female; behavior 


\section{Introduction}

Stress-related disorders such as depression and anxiety are common in pregnant women: 10 - $18 \%$ of pregnant women present with symptoms of depression, and 6-14\% present with symptoms of anxiety disorders [1-4]. This prevalence is even higher in pregnant women with lower socioeconomic status due to, in part, increased frequency of stressful life events [5-8]. Depression is a very stressful experience, it impacts a woman's sleep, eating, and self-care and the level of care she can provide to her child. Stress, depression, and anxiety during pregnancy can also lead to adverse obstetric outcomes and affect fetal and neonatal development and behaviour $[9,10]$.

Primary pharmacological treatments for anxiety and depression are selective serotonin reuptake inhibitors (SSRIs) [11]. Out of the $6 \%$ of pregnant women who are prescribed an SSRI at some point during their pregnancy, between $20-25 \%$ will receive fluoxetine (Flx; brand names Prozac, Sarafem, Rapiflux) [12].

Maternal intake of antidepressants and maternal anxiety, depression, and stress can affect obstetric outcomes and child's development and behaviour. Early exposure to these environmental events are linked with a decrease in gestational length and a reduction in birth weight [13-15], and may lead to changes in emotional behaviour, including anxiety, in children $[16,17]$. Beyond the childhood years, effects of maternal 
anxiety, depression, and stress and maternal Flx exposure are not yet fully understood.

Animal studies have been essential in uncovering these effects [for a review see 18, 19].

Animal studies utilize maternal stress as a model of maternal depression and anxiety. Studies show that maternal stress and maternal exposure to Flx both have longterm effects on the mouse and rat offspring. These maternal experiences alter offspring's learning and memory (stress: [20-25]; Flx: [26-28]), aggression levels (stress: [29-32]; Flx: [28, 32-34]), circadian behaviours (stress: [35]; Flx:[36]), and depressive- and anxiety-like behaviours (stress: [25, 37-39]; Flx: [26-28, 40-43]).

While necessary, examining the offspring of healthy animals is of minor ethological validity when attempting to draw inferences about exposed humans. This is because Flx exposure in humans does not typically happen in isolation; Flx exposure is concurrent with maternal stress, anxiety, and/or depression. Animal studies are beginning to examine combined effects of perinatal stress and Flx exposure on adult offspring outcomes. Some studies demonstrate that Flx and stress have specific long-term effects on the offspring. They have distinct effects on reproductive behaviour [44, 45], sexual brain differentiation [44], and depressive-like behaviour [46] in rats, and anxiety-like behaviour $[32,46]$ and hippocampal and cortical BDNF signaling in rats and mice [32, 46]. Other studies demonstrate that while maternal exposure to stress and Flx can have distinct effects, treatment with Flx early in life can counteract some of the effects of maternal stress. In mice, these include alterations in spatial learning [47], HPA-axis reactivity [48], aggressive behaviours [32], and circadian behaviours [35], while in rats, it includes sensitivity to post-operative pain [49]. In both rodent models, Flx counteracts 
stress-induced alterations in hippocampal morphology [47, 50]. However, most behavioural studies were conducted in male offspring; behaviours of adult female offspring have not yet been examined aside from reproductive [45] and depressive-like behaviours of rats [46]. A thorough assessment of outcomes in female offspring is warranted. Past studies provided indications that outcomes of female offspring may differ from that of males. First, behavioural baselines show sexual dimorphism [51-53]. Second, male and female animals are differently affected by stress [54-57] and Flx administration [58-60]. And, most importantly, male and female mice show different patterns of behavioural changes following maternal stress [22, 23, 61-65] and perinatal Flx administration $[43,63,66]$.

The goal of the present study was to investigate the effects of prenatal stress and effects of perinatal exposure to Flx, separately and in combination, on the behaviour of the adult female offspring. This study sought to provide a more complete insight by conducting an in-depth behavioural analysis of the offspring's cognitive ability, memory, anxiety, sensorimotor information processing, and exploratory and risk assessment behaviours.

\section{Methods}

\subsection{Animals}

All mice were kept on a 12:12-h light/dark (LD, 1,500 lx/0 lx) and were provided ad libitum access to food (LabDiet Mouse Diet 9F, \#5020) and water throughout the experiment with the exception of stress manipulation measures (see below). Animal 
treatment and husbandry were performed in accordance with the Canadian Council on Animal Care. All experimental procedures were approved by the Ethics Committee for Animal Research at the University of Calgary.

C57BL/6 breeders were obtained from the University of Calgary Biological Sciences breeding facility (Calgary, AB, Canada) and the Charles River animal facility (Wilmington, MA, USA; equally dispersed between treatment groups). At 3 months of age, male and female mice were paired in breeding triads (one male and two females) for a duration of 4 days. The day the seminal (copulation) plug was first observed was considered embryonic (E) day zero. The day of birth was considered to be postnatal (P) day 0 .

Pregnant dams were randomly assigned into four groups: (I) dams untreated (CON; n=6); (II) dams subjected to chronic unpredictable stress (PS; n=6); (III) dams administered Flx (FLX; n=5); (IV) dams subjected to PS and administered Flx (PS+FLX; $\mathrm{n}=6$ ). One day following parturition litters were culled to 8 pups (pups that were culled were picked randomly). Litters were housed together with their mother until weaning at P21 after which they were housed with same sex littermates in groups of 3-5. Final groups for behavioural testing consisted of 9 female mice per group; no more than 2 female pups were used from each litter. Male offspring were used in a different set of experiments.

\subsection{Chronic Unpredictable Stress Paradigm}


From E4 to E18, pregnant dams were subjected to a regimen of chronic unpredictable stressors (PS). The PS paradigm was modified from that used by Grippo and colleagues [67] and used as described in [32] and [35]. Stressors included restricted access to food (5- and 6-hour food deprivation; delivered during the day and overnight), continuous lighting overnight, cage tilt (home cage tilted 30 $\square$; delivered overnight or for 7 hours during the day), paired housing (animals were paired with another pregnant dam in either their home-cage or the other dam's cage, assigned in a counterbalanced fashion; delivered overnight), foreign object in cage (a novel plastic or glass object; overnight), soiled cage (100ml of clean water spilled on bedding; overnight), irregular $16 \mathrm{kHz}$ tones (played at 80dB; delivered for one hour during the day), white noise (played at 80dB; delivered for 3 hours during the day), and restraint (for the duration of two hours; delivered three times during the stress regimen). At least one and at most four stressors were delivered each day.

\subsection{Drug Treatment}

Between E15 and P12, pregnant dams were administered fluoxetine hydrochloride (Flx; Sigma-Aldrich, Saint Louis, MO, USA) in their drinking water at a dose of $25 \mathrm{mg} / \mathrm{kg} /$ day as previously described [28]. The Flx concentration in the water was based on the mouse's weight at the time and the mouse's water consumption for the preceding 48 hours. This concentration was re-calculated every $48 \mathrm{~h}$ to control for weight gain during the gestation period. This treatment protocol has been demonstrated to lead to pup brain levels of Flx and its metabolite norfluoxetine that fall within the range observed in post-mortem brain tissue of humans who took this medication [28]. 


\subsection{Measurement of Fluoxetine and Norfluoxetine in Pup Brains}

\subsubsection{Sample collection.}

Pup brains were collected at P12 (FLX: n=4, from 3 litters; PS+FLX: n=5, from 4 litters). After decapitation the brain was removed, the spinal cord was severed posterior to the cerebellum, and the olfactory bulbs were removed. Cortical structures (cortex and hippocampus) were peeled away from the thalamus and the subcortical portion was bisected between the cerebellum and inferior colliculus. The three resulting brain areas were separately frozen on dry ice and analyzed as: i. cortex and hippocampus, ii. thalamus/midbrain, and iii. hindbrain/cerebellum.

\subsubsection{Sample analysis.}

The sample preparation method was based on Raap et al. [68]. The concentrations of fluoxetine and norfluoxetine were quantified by high-performance liquid chromatography. Sample preparation and analysis were performed exactly as previously described [28].

\subsection{Behavioural Analysis}

A battery of well-validated behavioural tests was used to assess various patterns of adult behaviour in mice. The behavioural test battery we used was based upon previous reports assessing long term behavioural consequences of both stress and Flx treatments. Starting at 2 months of age, the offspring were administered behavioural tests 
assessing exploratory behaviour and locomotion, anxiety-related behaviours, sensorimotor gating and acoustic startle response, and spatial and fear memory.

Tests were performed in the following order: Open field and the elevated plus maze administered to all groups. The next three tests (Morris water test, passive avoidance, and prepulse inhibition) were conducted in a counterbalanced fashion, in that equal number of animals from each group received these tests in a different order. All testing was conducted during the light phase of the light-dark cycle, between 9am and $5 \mathrm{pm}$. Tests were conducted five to seven days apart.

\subsubsection{Open Field}

The open field task assesses an animal's movement in a large brightly lit, walled arena. By analyzing speed and distance travelled, differences in locomotor activity between groups can be measured and a comparison of time spent adjacent to the arena walls (thigmotaxis) and time spent in the arena's center provide a relative measure of anxiety [69].

In the current experiment a $1.2 \mathrm{~m}$ diameter brightly lit $(170 \pm 301 \mathrm{ux})$ white Plexiglas arena surrounded by a $35 \mathrm{~cm}$ high wall was used. Mice were placed individually in the arena's center and allowed to explore for $5 \mathrm{~min}$. Locomotor activity was recorded using an overhead mounted camera and HVS Image 2020 Plus software (HVS Image Ltd, Twickenham, Middlesex, UK). Thigmotaxis (Percent of time spent in the outer third of the arena), total distance traveled, and speed were measured. Following each trial the arena was cleaned using a $70 \%$ ethanol solution to remove olfactory cues. 


\subsubsection{Elevated Plus Maze}

The elevated plus maze test was conducted as previously described [28, 70, 71]. The elevated plus maze (EPM) test is a well-validated measure of anxiety-like behaviour in rodents [72]. The plus-shaped platform consists of two opposing enclosed arms $(5 \mathrm{~cm} \mathrm{x}$ $28 \mathrm{~cm})$ and two opposing open arms $(5 \mathrm{~cm} \mathrm{x} 28 \mathrm{~cm})$ extending outward, at right angles, from a central platform $(5 \mathrm{~cm} \times 5 \mathrm{~cm})$ elevated $28 \mathrm{~cm}$ above the floor; the platform was illuminated evenly by an overhead light ( $75 \pm 8$ lux). Animals were placed individually in the maze center facing an open arm then allowed to freely explore for $5 \mathrm{~min}$.

The percent of total time a mouse spent on the open arms, in the center or on closed arms, as well as the number of entries into open and closed arms, speed and distance travelled were measured using ANY-maze software version 4.73 (Stoelting Company, Wood Dale, Illinois, USA). Arm entry was operationally defined as 4 paws within an arm, or $95 \%$ of animal within an arm. Scanning behaviour (head dip), instances on the open arms when the animal looked over the edge towards the floor, and risk assessment behaviours (protective stretch), instances in which the animal stretched its head and forepaws into an open arm from a closed arm or the center space without making a full entry into the open arm were scored manually by the researcher [73]. The number of entries into open and closed arms, speed, distance, and time spent active were also taken as a measure of locomotor activity [74].

\subsubsection{Morris Water Task}


The Morris water task was conducted as previously described [32]. Briefly, MWT pool was white in color, $1.2 \mathrm{~m}$ in diameter and filled with water $\left(19.5 \pm 0.5^{\circ} \mathrm{C}\right)$ to a depth of $20 \mathrm{~cm}$. A clear plexiglas, square platform (20 x 16) was positioned in the center of one quadrant with the surface $1.5 \mathrm{~cm}$ below the water's surface. The water was made opaque by adding skim milk powder. Animals were video recorded from overhead using HVS Image 2020 Plus software (HVS Image Ltd, Twickenham, Middlesex, UK).

During the first four training days, the mice were subjected to four trials each day, where they were placed into the pool facing the wall at one of the cardinal compass points, chosen in a pseudo-random order (N/S/E/W). Each trial lasted 60s and was followed by a 15 s learning period where the mouse stayed atop the platform. Trials were separated by a 7-minute inter-trial interval. Trials were analyzed for speed, distance travelled, and latency to find the platform.

On the fifth day (probe trial) the platform was removed from the pool and animals were placed in a novel start location and given 60 s to swim freely. The initial latency to where the platform had been training days was recorded. Furthermore, the number of times the mouse swam through the area of platform's previous location (across or within one body space) was counted and analyzed.

\subsubsection{Passive Avoidance}

Animals were placed individually in a white Plexiglas chamber with a metal grate floor $(20.32 \mathrm{~cm} \mathrm{x} 25.4 \mathrm{~cm} \times 35.71 \mathrm{~cm})$, part of the dual-chamber LM1000-B avoidance system (Hamilton-Kinder LLC, San Diego, CA). Following acclimatization (2 min) the 
chamber door opened, allowing animals to enter a second dark chamber (black walls and roof) with the same metal grate floor. When the mouse had all four paws within the dark chamber, it was administered a mild foot shock $(0.5 \mathrm{~mA}$, duration $1 \mathrm{~s})$ through the metal floor. Twenty-four hours later the animals were placed individually within the white chamber with the door to the dark chamber already opened. Latency to enter the dark chamber was recorded for a maximum of $3 \mathrm{~min}$.

\subsubsection{Prepulse Inhibition}

Prepulse inhibition (PPI) is a measure of the magnitude of acoustic startle response to a stimulus when it is preceded by a weaker, sub-threshold stimulus (prepulse). PPI is a well validated measure of attentional impairments, sensory processing, and sensorimotor gating, known to be disrupted in various forms of psychopathology (Crawley, 2007). PPI and acoustic startle response were analyzed using the SM100SP Startle Monitor system (Hamilton-Kinder LLC; San Diego, CA, USA). The apparatus consisted of a sound-attenuated chamber $(27.6 \mathrm{~cm} \times 35.6 \mathrm{~cm} \times 49.5 \mathrm{~cm})$ housing a clear plexiglas chamber $(10 \mathrm{~cm} \times 3.8 \mathrm{~cm})$ with a piezoelectric motion monitor. Mice were placed into the chamber, provided a 5 min acclimatization period with a $65 \mathrm{~dB}$ steady ambient noise presented. Following this acclimatization period, a habituation phase took place in which a sound of $120 \mathrm{~dB}$ (duration 40ms) was delivered 10 times every 5-20s. Following habituation, the testing phase occurred where 3 types of trials were each presented 10 times separated by 5-20s intervals. The trials consisted of (i) no pulse, (ii) pulse alone (120dB, duration $40 \mathrm{~ms})$, and (iii) prepulse (80dB, duration $20 \mathrm{~ms}$ ) followed by a pulse (120dB, duration 40ms; 100ms interval). Percent PPI was calculated using the 
formula: 100-(100 x startle amplitude on prepulse trial)/startle amplitude on pulse alone trial. The animal's average startle response to a pulse, as well as percent PPI, were analyzed.

\subsubsection{Fear Conditioning}

Fear conditioning paradigms based on Pavlovian conditioning were used to assess learning and memory of a negative stimulus (foot shock). Mice experienced the pairing of a novel stimulus (tone) and context (chamber) with an adverse event (foot shock). Contextual and cued fear conditioned responses were assessed using a dual-chamber LM1000-B avoidance system (Hamilton-Kinder LLC, San Diego, CA) following a testing procedure modified from that used by Saxe and colleagues [75], as detailed below. Experiments took place across 3 days and consisted of a conditioning day, a cued fear memory testing day, and a contextual fear memory testing day.

On the conditioning day, mice were placed within the conditioning chamber $(20.32 \mathrm{~cm} \times 25.4 \mathrm{~cm} \times 35.71 \mathrm{~cm})$ for a $2-\mathrm{min}$ habituation period. They then received 3 pairings, at $2 \mathrm{~min}$ intervals, of $80 \mathrm{~dB}$ tones (duration 20s; conditioned stimulus) that terminated with a mild foot shock (0.5mA, duration $1 \mathrm{~s}$; unconditioned stimulus). The following day, contextual fear conditioning was assessed. On this day the mice were placed back into the chamber in which they had experienced the initial pairings of shock and tone for $4 \mathrm{~min}$, and freezing behaviour (absence of motor movement aside from breathing) in response to the original conditioning context was assessed across the entire session. The mice experienced neither tone nor foot shock on the contextual fear conditioning day. On the third day mice were placed in an environmentally altered 
chamber (color of walls (black to white), scent of environment (neutral to coconut), disinfectant used (70\% ethanol to Virkon), experimenter glove material (latex to nitrile), floor of chamber (from metal to plastic) to reduce contextual cues. Following a $2 \mathrm{~min}$ habituation period, mice were exposed to an $80 \mathrm{~dB}$ tone (duration $40 \mathrm{~s}$ ) that was not followed by a foot shock. Freezing behaviour in response to the conditioned stimulus (tone) was assessed one minute before the tone through the 40s duration of the tone. On the second and third days (contextual and cued fear conditioning) mice were recorded using an overhead camera (Sony DCR-TRV10), which were analyzed for freezing behaviour using ANY-maze software version 4.73 (Stoelting Company, Wood Dale, Illinois, USA).

\subsection{Data Analysis}

Tests that involved a single measurement (i.e., open field, elevated plus maze, prepulse inhibition) were analysed using a two-way (fluoxetine $\mathrm{x}$ stress) factorial analysis of variance (ANOVA). For tasks that involved repeated testing of the animals (e.g., passive avoidance, Morris water test, and levels of serotonin, Flx and NorFlx in different brain regions) a split plot ANOVA was computed. Tukey's post hoc test for multiple comparisons was used to assess differences between individual treatment groups.

Protected t-tests using the Bonferroni correction were used for multiple comparisons when following up main effects in repeated measurements (e.g., Morris water test). To examine whether litter effects contributed to any of the significant findings, all significant treatment effects were followed up $(p<0.05)$ with a nested ANOVA, this assessed the effect of litter nested within group. We failed to find any significant litter effects $(p>.10)$ 
(data not shown). All statistics were two-tailed. Values of $p<0.05$ were considered significant. All data and all figures are reported as means \pm standard error of the mean (SEM).

\section{Results}

\subsection{Actual Dose of Fluoxetine}

Increased water consumption throughout pregnancy and lactation resulted in an actual mean Flx dose of $27.42 \pm .55 \mathrm{mg} / \mathrm{kg} /$ day, instead of intended $25 \mathrm{mg} / \mathrm{kg} /$ day. Administered Flx dosage did not significantly differ between FLX and FLX+PS groups, and there was no significant group by day interaction.

\subsection{Fluoxetine and Norfluoxetine in Pup Brains}

In the P12 offspring that were exposed to fluoxetine, the mean brain fluoxetine level was $0.361 \pm 0.06 \mu \mathrm{g} / \mathrm{g}$ and the overall brain level of NorFlx was $3.73 \pm 0.33 \mu \mathrm{g} / \mathrm{g}$. There was no significant difference among brain regions in fluoxetine or NorFlx concentration.

\subsection{Behavioural Evaluation of Adult Animals}

\subsubsection{Open Field}

There was no effect of PS, Flx treatment, or PS by Flx treatment interaction on thigmotactic behaviour, speed and distance travelled in the open field (see Table 1A). 


\subsubsection{Elevated Plus Maze}

There was no effect of PS, Flx administration, or PS by Flx interaction on any measures on the EPM (see Table 1A).

\subsubsection{Passive Avoidance}

It took longer for mice to enter the dark chamber on day two, compared to day one $\left(F_{(1,32)}=119.10, p<.001\right)$ indicating that all mice learned the dark chamber/shock association (see Table 1B). The proportion of mice that entered the dark chamber on day two was not affected by perinatal Flx administration $\left(\chi^{2}(1, N=36)=.423, p=.691\right)$, or by PS $\left(\chi^{2}(1, N=36)=.423, p=.691\right)$.

\subsubsection{Prepulse Inhibition}

Female offspring of prenatally stressed dams had a higher PPI $(44.1 \pm 9.2 \%)$ compared to offspring of non-stressed dams $\left(29.8 \pm 14.3 \% ; F_{(1,32)}=13.00, p=.001 ;\right.$ Fig 1$)$. There was no effect of perinatal Flx exposure or PS by Flx interaction on PPI. Furthermore, no effect of PS, Flx administration, or PS by Flx interaction was observed on the startle response.

\subsubsection{Morris Water Task}

Latency to reach the platform decreased with training, indicating that all mice were able to learn the task $\left(F_{(3,96)}=81.37, p<.001\right.$; Fig $\left.2 \mathrm{~A}\right)$. While there was a significant effect of Flx on latency to reach the platform during the training days $\left(F_{(1,32)}=\right.$ $6.13, p=.019 ;$ Fig $2 \mathrm{~A}$ ), with Flx exposed animals reaching the platform slower than non- 
Flx exposed animals, after correcting for multiple comparisons, there was no significant difference between Flx exposed and non-exposed animals on latency to reach the platform on any of the training days (day1: $t_{(34)}=2.07, p=.046$; day $2: t_{(34)}=1.58, p$ $=.123 ;$ day3: $t_{(34)}=1.86, p=.071 ;$ day4: $\left.t_{(34)}=.75, p=.460\right)$. Female offspring of stressed dams swam faster $(.176 \pm .005 \mathrm{~m} / \mathrm{s})$ than offspring of dams not subjected to PS $\left(.161 \pm .005 \mathrm{~m} / \mathrm{s} ; F_{(1,32)}=5.04, p=.032 ; \mathrm{Fig} 2 \mathrm{~B}\right)$. During the probe trial, mice perinatally exposed to Flx crossed the platform area significantly more times (Flx-exposed:2.7 \pm 1.4 ; not exposed to Flx:1.5 $\pm .92 ; F_{(1,32)}=9.98, p=.003$; Fig $\left.2 \mathrm{C}\right)$ and found the platform faster (Flx-exposed:17.7 $\pm 16.7 \mathrm{~s}$; not exposed to Flx:31.5 $\pm 24.1 \mathrm{~s} ; F_{(1,32)}=4.18, p=.049 ;$ Fig $\left.2 \mathrm{D}\right)$ than mice not exposed to Flx (see Table 1B).

\section{Discussion}

Here, we show that chronic unpredictable maternal stress leads to increased activity and alterations of PPI in the adult female mouse offspring. We also demonstrate that perinatal maternal fluoxetine treatment appears to have little effect on female mice in the behavioural test we have used, potentially having beneficial effects on spatial memory. We further show that the combination of prenatal stress and perinatal Flx exposure did not interact in their effects. We have previously demonstrated no alterations in the maternal behaviour of dams following exposure to stress, Flx, or their combination [32], therefore, behavioural alterations observed in this study are unlikely to be caused by changes in maternal care received by experimental animals.

During early development, the brain is particularly vulnerable to maternal stress; maternal stress is known to lead to short- and long- term changes in offspring brain and 
behaviour. Maternal stress is linked with higher incidence of neuropsychiatric disorders [76-78], as well as multiple alterations in offspring neuroanatomy and behaviour. The challenge of interpreting the long-term effects of PS is the variation of experimental methods which leads to inconclusive results. Preclinical studies offer no consistent results on the effects of maternal stress on prepulse inhibition and activity levels of adult offspring.

In this study, we found that chronic unpredictable stress administered to C57BL/6 dams from E4 to E18 led to increased activity amongst their female offspring. Mice exposed to PS swim faster in the MWT, and tend to travel longer distances at higher speeds in the EPM. Similar findings have been reported in clinical studies where maternal prenatal stress is linked to childhood attention deficit hyperactivity disorder (ADHD) in their female children $[79,80]$. Animal studies also report increased activity in perinatally stressed male [20, 39, 81] and female [25] offspring. In adult animals, chronic stress exposure also leads to increased activity, suggesting a possibility of a common mechanism where early and late-life stress both increase activity levels, however, only male mice have been examined in this regard [82-84].

We found that female mice exposed to PS exhibit increased prepulse inhibition. Lehmann [24] found that prenatally stressed adult female rats similarly show increased PPI. However, the opposite effect of PS on PPI of female rats has also been reported [85]. In humans, PPI alterations are associated with a number of psychiatric disorders [for a review see 86]; increased PPI in females (but not males) is associated with bipolar disorder [87]. Interestingly, PS is linked to bipolar disorder in humans [88]. Like the 
female mice in our study, human females (but not males) with bipolar disorder have increased PPI [87].

Here, and in previous papers, we show that Flx administration to a dam leads to detectable fluoxetine and norfluoxetine levels in pup brains [28]. Perinatal exposure to Flx has a number of long-term effects on offspring. Studies of male animals show changes in circadian activity, cocaine sensitivity, depressive-like behaviour, anxiety-like behaviour, fear memory, thermal sensitivity, sexual motivation, and copulatory behaviours [for a review see 19]. Few studies examine the effect that exposure to Flx early in development has on behaviour of adult female offspring. At this time, an increase in copulatory behaviour [49], increases and decreases and depressive-like behaviours [43, 70], and a decrease or no change in anxiety-like behaviour have been reported [43, 70, 89].

Independent of stress, perinatal exposure to Flx had only minor effects on the offspring's behaviour as adults. In the probe trial of MWT, Flx-exposed mice crossed the platform location more times and found the platform location faster than mice not exposed to Flx. Improved MWT performance following perinatal Flx exposure was previously demonstrated in male mice [28], and adolescent male and female rats [90]. Because spatial memory performance is correlated with hippocampal neurogenesis [for a review see 91], the enhancement in the MWT performance may be related to Flx-induced alterations in hippocampal neurogenesis [92-94]. Maternal Flx treatment had no effect on female offspring's cognitive ability, anxiety, sensorimotor information processing, and exploratory and risk assessment behaviours. 
The comparison of our findings to those of males is imperative. The optimal benchmark is our earlier studies in males, as identical stress and Flx treatment protocols were used. Some behavioural changes appear to be sex-dependent. For example, PS has disparate effects on PPI; unlike in males, PPI of female mice is altered by PS [28, 32]. Flx also has sexually-dimorphic effects on anxiety behaviour, having an anxiolytic effect in male, but not female mice $[28,32]$. While sex-differences in the effects of stress and Flx are observed, some similarities also exist. PS causes increased activity, while Flx has the potential to improve spatial memory in mice of both sexes [28, 32, 35]. At present, not all behaviours have been studied in mice of both sexes. For example, aggression and circadian behaviours have not yet been examined in female mice exposed to PS and Flx. In males, PS and Flx interact in their effect on these behaviours [32, 35], therefore, examination of aggression and circadian behaviours in females is needed.

While it is becoming clearer that PS, Flx, and their combination lead to different behavioural changes in males and females, the mechanism of such sexually dimorphic changes is not yet understood. A combination of stress-induced changes in maternal glucocorticoids, opioid peptides, and catecholamines may have distinct effects on the development of male vs female offspring brain [95] and may also have the ability to directly alter sexually dimorphic brain areas [44] explaining different outcomes in female and male animals exposed to PS. Furthermore, alterations in the serotonergic system may underlie sex-dependent changes that follow Flx exposure [32, 66, 96]. More research is needed to fully understand the mechanism of sexually dimorphic behavioural changes that follow exposure to PS, Flx, and their combination. 


\section{Conclusion}

Due to the high percentage of pregnant women that take Flx, it is important to understand the effect this medication alone, and in combination with maternal stress and depression, has on the offspring. Few studies examine combined effects of stress and Flx, and most of the studies that exist examine only the outcomes of male offspring. In the present study, we report that maternal stress has a number of long-lasting, potentially negative, effects on female mouse offspring. We also report that fluoxetine has very few effects on female mouse offspring, and may even be beneficial due to its potential to improve spatial memory. We further show that, in female offspring, Flx did not worsen nor reverse the effects of maternal stress. Our findings indicate that maternal intake of Flx may have a limited impact on female mouse offspring, however more research is necessary to clearly understand the mechanism of such effects and its translation to humans. 
Table 1A: Summary of results of behavioural testing battery demonstrating effects of prenatal stress and perinatal fluoxetine exposure on behaviour of female mice as adults

\begin{tabular}{|c|c|c|c|c|c|c|c|}
\hline Behavioural Test & Control & Fluoxetine & Stress & $\begin{array}{l}\text { Stress+ } \\
\text { Fluoxetine }\end{array}$ & Main Effect of Flx & Main Effect of Stress & Flx and Stress Interaction \\
\hline \multicolumn{8}{|l|}{ Open Field } \\
\hline Thigmotaxis time (\%) & $60.35 \pm 4.02$ & $69.48 \pm 4.27$ & $53.03 \pm 6.60$ & $56.78 \pm 5.75$ & $F_{(1,32)}=1.49, p=.231$ & $F_{(1,32)}=3.61, p=.066$ & $F_{(1,32)}=.26, p=.613$ \\
\hline Speed $(\mathrm{m} / \mathrm{s})$ & $.11 \pm .001$ & $.11 \pm .010$ & $.086 \pm .002$ & $.11 \pm .011$ & $F_{(1,32)}=1.42, p=.242$ & $F_{(1,32)}=3.20, p=.083$ & $F_{(1,32)}=1.15, p=.291$ \\
\hline Distance (m) & $33.29 \pm 3.42$ & $34.41 \pm 2.93$ & $26.02 \pm .96$ & $32.12 \pm 2.93$ & $F_{(1,32)}=1.75, p=.196$ & $F_{(1,32)}=3.06, p=.090$ & $F_{(1,32)}=.828, p=.370$ \\
\hline \multicolumn{8}{|l|}{$\overline{\text { Elevated Plus Maze }}$} \\
\hline Open arm time $(\%)$ & $10.87 \pm 3.12$ & $8.71 \pm 1.34$ & $14.29 \pm 4.51$ & $14.09 \pm 3.77$ & $F_{(1,32)}=.12, p=.730$ & $F_{(1,32)}=1.67, p=.205$ & $F_{(1,32)}=.08, p=.776$ \\
\hline Open arm entry & $5.33 \pm 1.37$ & $4.22 \pm 0.52$ & $5.89 \pm 1.02$ & $5.22 \pm 1.24$ & $F_{(1,32)}=.67, p=.421$ & $F_{(1,32)}=.51, p=.481$ & $F_{(1,32)}=.04, p=.840$ \\
\hline Closed arm entry & $9.00 \pm .86$ & $11.22 \pm 1.63$ & $11.67 \pm 1.04$ & $12.56 \pm 1.41$ & $F_{(1,32)}=1.49, p=.231$ & $F_{(1,32)}=2.46, p=.126$ & $F_{(1,32)}=.27, p=.605$ \\
\hline Speed $(\mathrm{m} / \mathrm{s})$ & $.018 \pm .001$ & $.021 \pm .002$ & $.023 \pm .001$ & $.023 \pm .002$ & $F_{(1,32)}=.12, p=.731$ & $F_{(1,32)}=3.22, p=.082$ & $F_{(1,32)}=.75, p=.392$ \\
\hline Distance (m) & $5.57 \pm .45$ & $6.23 \pm .70$ & $7.07 \pm .48$ & $6.81 \pm .63$ & $F_{(1,32)}=.12, p=.728$ & $F_{(1,32)}=3.27, p=.080$ & $F_{(1,32)}=.63, p=.435$ \\
\hline Time active $(\%)$ & $55.23 \pm 13.66$ & $57.41 \pm 10.43$ & $63.84 \pm 6.19$ & $61.09 \pm 13.30$ & $F_{(1,32)}=.01, p=.941$ & $F_{(1,32)}=2.65, p=.113$ & $F_{(1,32)}=.43, p=.517$ \\
\hline Protected stretches & $10.67 \pm 1.37$ & $11.22 \pm 0.86$ & $9.44 \pm 0.77$ & $11.22 \pm 1.23$ & $F_{(1,32)}=1.15, p=.292$ & $F_{(1,32)}=.315, p=.578$ & $F_{(1,32)}=.315, p=.578$ \\
\hline Head dips & $9.22 \pm 2.62$ & $9.00 \pm 1.63$ & $11.67 \pm 3.57$ & $11.44 \pm 2.76$ & $F_{(1,32)}=.01, p=.936$ & $F_{(1,32)}=.80, p=.379$ & $F_{(1,32)}=.000, p>.999$ \\
\hline \multicolumn{8}{|l|}{ Prepulse Inhibition } \\
\hline PPI (\%) & $34.36 \pm 4.39$ & $25.31 \pm 4.88$ & $44.86 \pm 3.50$ & $43.41 \pm 2.72$ & $F_{(1,32)}=1.75, p=.195$ & $F_{(1,32)}=13.00, \boldsymbol{p}=\mathbf{. 0 0 1}$ & $F_{(1,32)}=.918, p=.345$ \\
\hline Startle response & $.39 \pm .057$ & $.39 \pm .058$ & $.40 \pm .035$ & $.54 \pm .044$ & $F_{(1,32)}=1.97, p=.170$ & $F_{(1,32)}=2.88, p=.099$ & $F_{(1,32)}=1.59, p=.217$ \\
\hline
\end{tabular}

Note: Significant results $(p<0.05)$ are reported in bold font; $\mathrm{n}=9$ per group. All data are

presented as mean \pm SEM.

Table 1B: Summary of results of behavioural testing battery demonstrating effects of prenatal stress and perinatal fluoxetine exposure on behaviour of female mice as adults

\begin{tabular}{lllll}
\hline Behavioural Test & Main Effect of Flx & Main Effect of Stress & Flx and Stress Interaction Effect of Time \\
\hline $\begin{array}{l}\text { Passive avoidance } \\
\text { Latency }\end{array}$ & $F_{(1,32)}=.91, p=.347$ & $F_{(1,32)}=1.20, p=.282$ & $F_{(1,32)}=3.24, p=.081$ & $F_{(1,32)}=119.10, p<.001$ \\
\hline
\end{tabular}

\section{Morris Water Task}

Training Days

$\begin{array}{lllll}\text { Latency } & F_{(1,32)}=6.13, \boldsymbol{p}=. \mathbf{0 1 9} & F_{(1,32)}=1.01, p=.323 & F_{(1,32)}=.002, p=.967 & F_{(3,96)}=81.37, \boldsymbol{p}<.001 \\ \text { Speed } & F_{(1,32)}=.03, p=.865 & F_{(1,32)}=5.04, \boldsymbol{p}=. \mathbf{0 3 2} & F_{(1,32)}=.34, p=.562 & \\ \text { Thigmotaxis } & F_{(1,32)}=1.63, p=.211 & F_{(1,32)}=1.46, p=.235 & F_{(1,32)}=.06, p=.804\end{array}$

Probe Trial

Latency $\quad F_{(1,32)}=4.18, \boldsymbol{p}=\mathbf{. 0 4 9} \quad F_{(1,32)}=0.96, p=.333 \quad F_{(1,32)}=.33, p=.572$

Time Crossed $\quad F_{(1,32)}=9.98, \boldsymbol{p}=\mathbf{. 0 0 3} \quad F_{(1,32)}=.17, p=.683 \quad F_{(1,32)}=.17, p=.683$

Note: Significant results $(p<0.05)$ are reported in bold font; $\mathrm{n}=9$ per group. All data are presented as mean \pm SEM. 
Figure 1. Prepulse inhibition. Adult female offspring of dams subjected to chronic variable stress show enhanced prepulse inhibition ( $\mathrm{n}=9$ per group); \# denotes significant main effect of stress, $p<0.05$. All data are presented as mean \pm SEM.

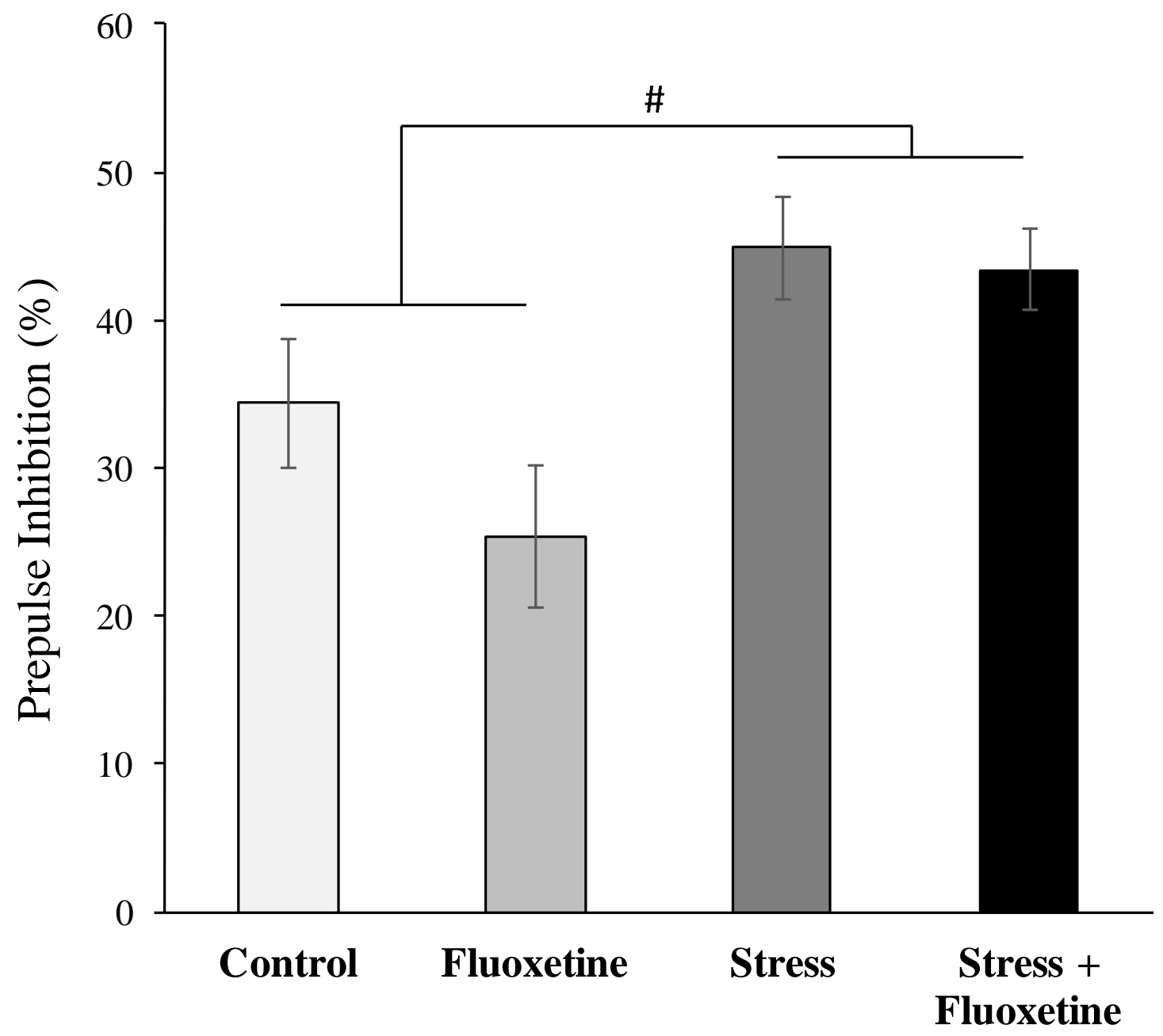


Figure 2. Performance in the Morris water task. Mean latency to reach the platform across 4 days of testing in the MWT (A). Offspring of mice exposed to chronic variable stress traveled with greater speed in the Morris water test (B). Maternal exposure to fluoxetine enhances spatial memory in adult female offspring. In the probe trial, Flx exposure led to an increase in number of crosses of platform's location (C), and lead to a shorter latency to find platform's location (D). $n=9$ per group; \# denotes significant main effect of stress; * denotes a significant main effect of fluoxetine; \# and $* p<0.05$. All data are presented as mean \pm SEM.
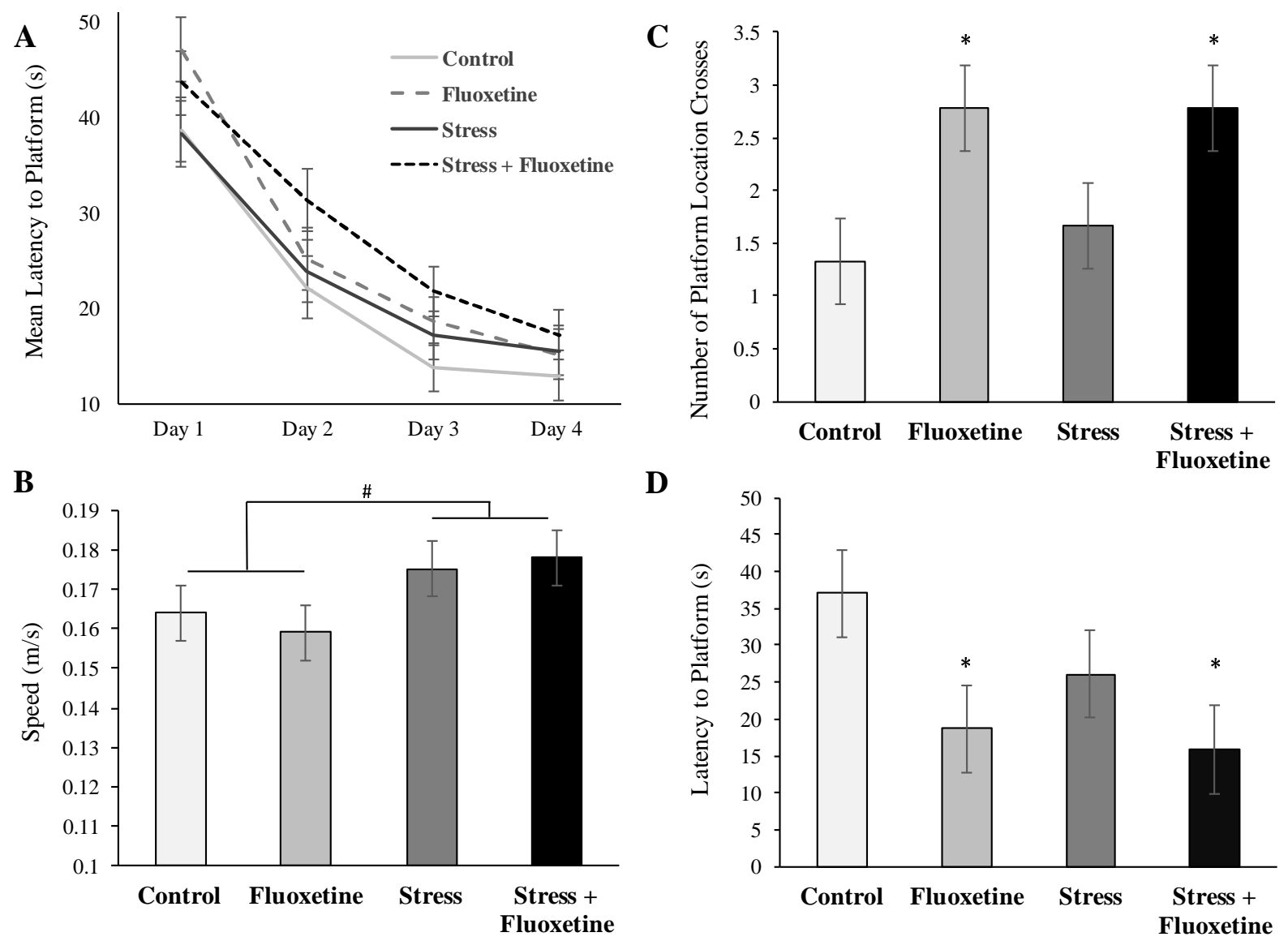

D

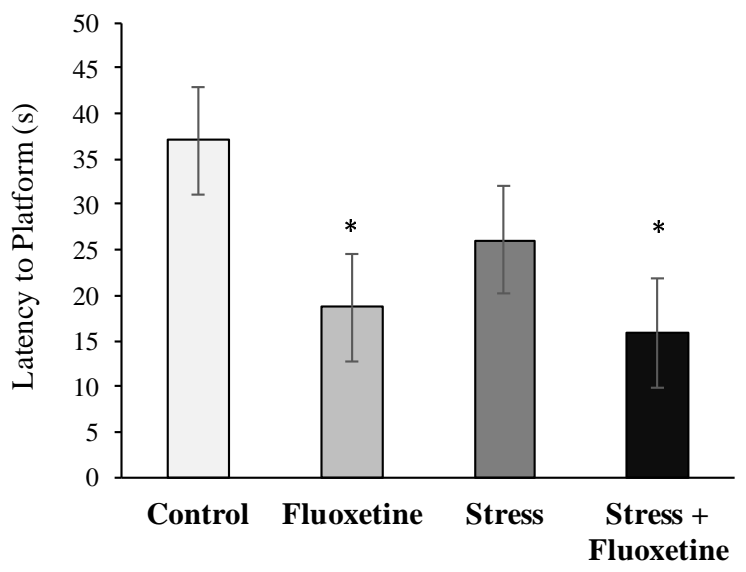




\section{References}

[1] L. Andersson, I. Sundström-Poromaa, M. Bixo, M. Wulff, K. Bondestam, M. åStröm, Point prevalence of psychiatric disorders during the second trimester of pregnancy: a population-based study, American Journal Of Obstetrics And Gynecology 189(1) (2003) 148-154.

[2] N.I. Gavin, B.N. Gaynes, K.N. Lohr, S. Meltzer-Brody, G. Gartlehner, T. Swinson, Perinatal depression - A systematic review of prevalence and incidence, Obstetrics and Gynecology 106(5) (2005) 1071-1083.

[3] T. Kitamura, S. Shima, M. Sugawara, M.A. Toda, Psychological and Social Correlates of the Onset of Affective-Disorders among Pregnant-Women, Psychol Med 23(4) (1993) 967-975.

[4] L.E. Ross, L.M. McLean, Anxiety disorders during pregnancy and the postpartum period: A systematic review, J Clin Psychiatry 67(8) (2006) 1285-98.

[5] S.E. Hobfoll, C. Ritter, J. Lavin, M.R. Hulsizer, R.P. Cameron, Depression prevalence and incidence among inner-city pregnant and postpartum women, Journal Of Consulting And Clinical Psychology 63(3) (1995) 445-453.

[6] M.D. McKee, M. Cunningham, K.R. Jankowski, L. Zayas, Health-related functional status in pregnancy: relationship to depression and social support in a multi-ethnic population, Obstetrics And Gynecology 97(6) (2001) 988-993.

[7] A. Wenzel, E.N. Haugen, L.C. Jackson, J.R. Brendle, Anxiety symptoms and disorders at eight weeks postpartum, J Anxiety Disord 19(3) (2005) 295-311.

[8] C. Borri, M. Mauri, A. Oppo, S. Banti, C. Rambelli, D. Ramacciotti, M.S. Montagnani, V. Camilleri, S. Cortopassi, A. Bettini, S. Ricciardulli, P. Rucci, S.

Montaresi, G.B. Cassano, Axis I psychopathology and functional impairment at the third month of pregnancy: Results from the Perinatal Depression-Research and Screening Unit (PND-ReScU) study, J Clin Psychiatry 69(10) (2008) 1617-24.

[9] J. Alder, N. Fink, J. Bitzer, I. Hosli, W. Holzgreve, Depression and anxiety during pregnancy: a risk factor for obstetric, fetal and neonatal outcome? A critical review of the literature, J Matern Fetal Neonatal Med 20(3) (2007) 189-209.

[10] C. Dunkel Schetter, L. Tanner, Anxiety, depression and stress in pregnancy: implications for mothers, children, research, and practice, Curr Opin Psychiatry 25(2) (2012) 141-8.

[11] R. Mandrioli, L. Mercolini, M.A. Saracino, M.A. Raggi, Selective Serotonin Reuptake Inhibitors (SSRIs): Therapeutic Drug Monitoring and Pharmacological Interactions, Curr Med Chem 19(12) (2012) 1846-1863.

[12] S.E. Andrade, M.E. Reichman, K. Mott, M. Pitts, C. Kieswetter, M. Dinatale, M.B. Stone, J. Popovic, K. Haffenreffer, S. Toh, Use of selective serotonin reuptake inhibitors (SSRIs) in women delivering liveborn infants and other women of child-bearing age within the U.S. Food and Drug Administration's Mini-Sentinel program, Arch Womens Ment Health (2016).

[13] V. Hendrick, L.M. Smith, R. Suri, S. Hwang, D. Haynes, L. Altshuler, Birth outcomes after prenatal exposure to antidepressant medication, American Journal Of Obstetrics And Gynecology 188(3) (2003) 812-815. 
[14] C.D. Chambers, K.A. Johnson, L.M. Dick, R.J. Felix, K.L. Jones, Birth outcomes in pregnant women taking fluoxetine, The New England Journal Of Medicine 335(14) (1996) 1010-1015.

[15] N.K. Grote, J.A. Bridge, A.R. Gavin, J.L. Melville, S. Iyengar, W.J. Katon, A metaanalysis of depression during pregnancy and the risk of preterm birth, low birth weight, and intrauterine growth restriction, Arch Gen Psychiatry 67(10) (2010) 1012-24. [16] G.E. Hanley, U. Brain, T.F. Oberlander, Prenatal exposure to serotonin reuptake inhibitor antidepressants and childhood behavior, Pediatr Res 78(2) (2015) 174-80. [17] B.R. Van den Bergh, A. Marcoen, High antenatal maternal anxiety is related to ADHD symptoms, externalizing problems, and anxiety in 8- and 9-year-olds, Child Dev 75(4) (2004) 1085-97.

[18] J.D. Olivier, H. Akerud, H. Kaihola, J.L. Pawluski, A. Skalkidou, U. Hogberg, I. Sundstrom-Poromaa, The effects of maternal depression and maternal selective serotonin reuptake inhibitor exposure on offspring, Front Cell Neurosci 7 (2013) 73.

[19] V. Kiryanova, B.B. McAllister, R.H. Dyck, Long-term outcomes of developmental exposure to fluoxetine: a review of the animal literature, Dev Neurosci 35(6) (2013) 437 9.

[20] M. Vallee, W. Mayo, F. Dellu, M. LeMoal, H. Simon, S. Maccari, Prenatal stress induces high anxiety and postnatal handling induces low anxiety in adult offspring: Correlation with stress-induced corticosterone secretion, J Neurosci 17(7) (1997) 26262636.

[21] M. Vallee, S. Maccari, F. Dellu, H. Simon, M. Le Moal, W. Mayo, Long-term effects of prenatal stress and postnatal handling on age-related glucocorticoid secretion and cognitive performance: a longitudinal study in the rat, European Journal of Neuroscience 11(8) (1999) 2906-2916. [22] C. Bustamante, P. Bilbao, W. Contreras, M. Martinez, A. Mendoza, A. Reyes, R. Pascual, Effects of prenatal stress and exercise on dentate granule cells maturation and spatial memory in adolescent mice, Int J Dev Neurosci 28(7) (2010) 605-9.

[23] H. Nishio, S. Kasuga, M. Ushijima, Y. Harada, Prenatal stress and postnatal development of neonatal rats sex-dependent effects on emotional behavior and learning ability of neonatal rats, Int J Dev Neurosci 19(1) (2001) 37-45.

[24] J. Lehmann, T. Stohr, J. Feldon, Long-term effects of prenatal stress experiences and postnatal maternal separation on emotionality and attentional processes, Behav Brain Res 107(1-2) (2000) 133-44.

[25] T. Stohr, D. Schulte Wermeling, T. Szuran, V. Pliska, A. Domeney, H. Welzl, I. Weiner, J. Feldon, Differential effects of prenatal stress in two inbred strains of rats, Pharmacol Biochem Behav 59(4) (1998) 799-805.

[26] J.D.A. Olivier, A. Valles, F. van Heesch, A. Afrasiab-Middelman, J.J.P.M. Roelofs, M. Jonkers, E.J. Peeters, G.A.H. Korte-Bouws, J.P. Dederen, A.J. Kiliaan, G.J. Martens, D. Schubert, J.R. Homberg, Fluoxetine administration to pregnant rats increases anxietyrelated behavior in the offspring, Psychopharmacology 217(3) (2011) 419-432.

[27] T.J. Rebello, Q. Yu, N.M. Goodfellow, M.K. Caffrey Cagliostro, A. Teissier, E. Morelli, E.Y. Demireva, A. Chemiakine, G.B. Rosoklija, A.J. Dwork, E.K. Lambe, J.A. Gingrich, M.S. Ansorge, Postnatal day 2 to 11 constitutes a 5-HT-sensitive period impacting adult mPFC function, J Neurosci 34(37) (2014) 12379-93. 
[28] V. Kiryanova, R.H. Dyck, Increased aggression, improved spatial memory, and reduced anxiety-like behaviour in adult male mice exposed to fluoxetine early in life, Dev Neurosci 36(5) (2014) 396-408.

[29] C. Kinsley, B. Svare, Prenatal stress reduces intermale aggression in mice, Physiol Behav 36(4) (1986) 783-6.

[30] M.C. Tsuda, N. Yamaguchi, S. Ogawa, Early life stress disrupts peripubertal development of aggression in male mice, Neuroreport 22(6) (2011) 259-63.

[31] V. Patin, B. Lordi, A. Vincent, J. Caston, Effects of prenatal stress on anxiety and social interactions in adult rats, Brain Res Dev Brain Res 160(2) (2005) 265-74.

[32] V. Kiryanova, S.J. Meunier, H.A. Vecchiarelli, M.N. Hill, R.H. Dyck, Effects of maternal stress and perinatal fluoxetine exposure on behavioral outcomes of adult male offspring, Neuroscience 320 (2016) 281-96.

[33] Y. Singh, A.K. Jaiswal, M. Singh, S.K. Bhattacharya, Effect of prenatal diazepam, phenobarbital, haloperidol and fluoxetine exposure on foot shock induced aggression in rats, Indian J Exp Biol 36(10) (1998) 1023-4.

[34] N. Svirsky, S. Levy, R. Avitsur, Prenatal exposure to selective serotonin reuptake inhibitors (SSRI) increases aggression and modulates maternal behavior in offspring mice, Dev Psychobiol 58(1) (2016) 71-82.

[35] V. Kiryanova, V.M. Smith, R.H. Dyck, M.C. Antle, Circadian behavior of adult mice exposed to stress and fluoxetine during development, Psychopharmacology (Berl) (2016).

[36] V. Kiryanova, V.M. Smith, R.H. Dyck, M.C. Antle, The effects of perinatal fluoxetine treatment on the circadian system of the adult mouse, Psychopharmacology (Berl) 225(3) (2013) 743-51.

[37] S. Morley-Fletcher, J. Mairesse, A. Soumier, M. Banasr, F. Fagioli, C. Gabriel, E. Mocaer, A. Daszuta, B. McEwen, F. Nicoletti, S. Maccari, Chronic agomelatine treatment corrects behavioral, cellular, and biochemical abnormalities induced by prenatal stress in rats, Psychopharmacology (Berl) 217(3) (2011) 301-13.

[38] K. Miyagawa, M. Tsuji, K. Fujimori, Y. Saito, H. Takeda, Prenatal stress induces anxiety-like behavior together with the disruption of central serotonin neurons in mice, Neurosci Res 70(1) (2011) 111-117.

[39] O.J. Bosch, S.A. Kromer, I.D. Neumann, Prenatal stress: opposite effects on anxiety and hypothalamic expression of vasopressin and corticotropin-releasing hormone in rats selectively bred for high and low anxiety, Eur J Neurosci 23(2) (2006) 541-51.

[40] C. Mendes-da-Silva, S.L. de Souza, J.M. Barreto-Medeiros, S.R. de Freitas-Silva, D.E.C. Antunes, A.D.U. Cunha, V.R. Ribas, M.F.S. de França, M.I. Nogueira, R. Manhães-de-Castro, Neonatal treatment with fluoxetine reduces depressive behavior induced by forced swim in adult rats, Arquivos De Neuro-Psiquiatria 60(4) (2002) 928931.

[41] C.W. Noorlander, F.F.T. Ververs, P.G.J. Nikkels, C.J.A. van Echteld, G.H.A. Visser, M.P. Smidt, Modulation of serotonin transporter function during fetal development causes dilated heart cardiomyopathy and lifelong behavioral abnormalities, Plos One 3(7) (2008) e2782-e2782.

[42] N.N. Karpova, J. Lindholm, P. Pruunsild, T. Timmusk, E. Castren, Long-lasting behavioural and molecular alterations induced by early postnatal fluoxetine exposure are 
restored by chronic fluoxetine treatment in adult mice, Eur Neuropsychopharm 19(2) (2009) 97-108.

[43] S.F.S. Lisboa, P.E. Oliveira, L.C. Costa, E.J. Venancio, E.G. Moreira, Behavioral evaluation of male and female mice pups exposed to fluoxetine during pregnancy and lactation, Pharmacology 80(1) (2007) 49-56.

[44] I. Rayen, H.W. Steinbusch, T.D. Charlier, J.L. Pawluski, Developmental fluoxetine exposure and prenatal stress alter sexual differentiation of the brain and reproductive behavior in male rat offspring, Psychoneuroendocrinology 38(9) (2013) 1618-29. [45] I. Rayen, H.W. Steinbusch, T.D. Charlier, J.L. Pawluski, Developmental fluoxetine exposure facilitates sexual behavior in female offspring, Psychopharmacology (Berl) 231(1) (2014) 123-33.

[46] F. Boulle, J.L. Pawluski, J.R. Homberg, B. Machiels, Y. Kroeze, N. Kumar, H.W. Steinbusch, G. Kenis, D.L. van den Hove, Developmental fluoxetine exposure increases behavioral despair and alters epigenetic regulation of the hippocampal BDNF gene in adult female offspring, Horm Behav 80 (2016) 47-57.

[47] H. Ishiwata, T. Shiga, N. Okado, Selective serotonin reuptake inhibitor treatment of early postnatal mice reverses their prenatal stress-induced brain dysfunction, Neuroscience 133(4) (2005) 893-901.

[48] A.A. Salari, L. Fatehi-Gharehlar, N. Motayagheni, J.R. Homberg, Fluoxetine normalizes the effects of prenatal maternal stress on depression- and anxiety-like behaviors in mouse dams and male offspring, Behav Brain Res 311 (2016) 354-67. [49] L. Knaepen, I. Rayen, T.D. Charlier, M. Fillet, V. Houbart, M. van Kleef, H.W.

Steinbusch, J. Patijn, D. Tibboel, E.A. Joosten, J.L. Pawluski, Developmental Fluoxetine Exposure Normalizes the Long-Term Effects of Maternal Stress on Post-Operative Pain in Sprague-Dawley Rat Offspring, Plos One 8(2) (2013).

[50] I. Rayen, M. Gemmel, G. Pauley, H.W.M. Steinbusch, J.L. Pawluski, Developmental exposure to SSRIs, in addition to maternal stress, has long-term sexdependent effects on hippocampal plasticity, Psychopharmacology (Berl.) 232(7) (2015) 1231-44.

[51] C. Dalla, T.J. Shors, Sex differences in learning processes of classical and operant conditioning, Physiol Behav 97(2) (2009) 229-38.

[52] N. Kokras, C. Dalla, Sex differences in animal models of psychiatric disorders, Br J Pharmacol 171(20) (2014) 4595-619.

[53] S.J. Alonso, M.A. Castellano, D. Afonso, M. Rodriguez, Sex differences in behavioral despair: relationships between behavioral despair and open field activity, Physiol Behav 49(1) (1991) 69-72.

[54] J.A. Babb, C.V. Masini, H.E. Day, S. Campeau, Sex differences in activated corticotropin-releasing factor neurons within stress-related neurocircuitry and hypothalamic-pituitary-adrenocortical axis hormones following restraint in rats, Neuroscience 234 (2013) 40-52.

[55] M.Q. Steinman, S.A. Laredo, E.M. Lopez, C.E. Manning, R.C. Hao, I.E. Doig, K.L. Campi, A.E. Flowers, J.K. Knight, B.C. Trainor, Hypothalamic vasopressin systems are more sensitive to the long term effects of social defeat in males versus females, Psychoneuroendocrinology 51 (2015) 122-34.

[56] B.C. Trainor, M.C. Pride, R. Villalon Landeros, N.W. Knoblauch, E.Y. Takahashi, A.L. Silva, K.K. Crean, Sex differences in social interaction behavior following social 
defeat stress in the monogamous California mouse (Peromyscus californicus), PLoS One 6(2) (2011) e17405.

[57] G.D. Greenberg, A. Laman-Maharg, K.L. Campi, H. Voigt, V.N. Orr, L. Schaal, B.C. Trainor, Sex differences in stress-induced social withdrawal: role of brain derived neurotrophic factor in the bed nucleus of the stria terminalis, Front Behav Neurosci 7 (2013) 223.

[58] A. Fernandez-Guasti, M. Olivares-Nazario, R. Reyes, L. Martinez-Mota, Sex and age differences in the antidepressant-like effect of fluoxetine in the forced swim test, Pharmacol Biochem Behav (2016).

[59] M.L. Gomez, L. Martinez-Mota, E. Estrada-Camarena, A. Fernandez-Guasti, Influence of the brain sexual differentiation process on despair and antidepressant-like effect of fluoxetine in the rat forced swim test, Neuroscience 261 (2014) 11-22.

[60] K. Lebron-Milad, A. Tsareva, N. Ahmed, M.R. Milad, Sex differences and estrous cycle in female rats interact with the effects of fluoxetine treatment on fear extinction, Behav Brain Res 253 (2013) 217-22.

[61] P.J. Brunton, J.A. Russell, Prenatal social stress in the rat programmes neuroendocrine and behavioural responses to stress in the adult offspring: sex-specific effects, J Neuroendocrinol 22(4) (2010) 258-71.

[62] A.T. Behan, D.L. van den Hove, L. Mueller, M.J. Jetten, H.W. Steinbusch, D.R. Cotter, J. Prickaerts, vidence of female-specific glial deficits in the hippocampus in a mouse model of prenatal stress, Eur Neuropsychopharm 21(1) (2011) 71-9.

[63] J.L. Pawluski, D.L. van den Hove, I. Rayen, J. Prickaerts, H.W. Steinbusch, Stress and the pregnant female: Impact on hippocampal cell proliferation, but not affective-like behaviors, Horm Behav 59(4) (2011) 572-80.

[64] B.R. Mueller, T.L. Bale, Early prenatal stress impact on coping strategies and learning performance is sex dependent, Physiol Behav 91(1) (2007) 55-65.

[65] B.R. Mueller, T.L. Bale, Sex-specific programming of offspring emotionality after stress early in pregnancy, J Neurosci 28(36) (2008) 9055-65.

[66] P.d.N. Favaro, L.C. Costa, E.G. Moreira, Maternal fluoxetine treatment decreases behavioral response to dopaminergic drugs in female pups, Neurotoxicology And Teratology 30(6) (2008) 487-494.

[67] A.J. Grippo, T.G. Beltz, A.K. Johnson, Behavioral and cardiovascular changes in the chronic mild stress model of depression, Physiol. Behav. 78(4-5) (2003) 703-10.

[68] D.K. Raap, F. Garcia, N.A. Muma, W.A. Wolf, G. Battaglia, L.D. van de Kar, Sustained desensitization of hypothalamic 5-Hydroxytryptamine1A receptors after discontinuation of fluoxetine: inhibited neuroendocrine responses to 8-hydroxy-2(Dipropylamino)Tetralin in the absence of changes in Gi/o/z proteins, J. Pharmacol. Exp. Ther. 288(2) (1999) 561-7.

[69] J. Archer, Tests for emotionality in rats and mice: a review, Anim Behav 21(2) (1973) 205-35.

[70] B.B. McAllister, V. Kiryanova, R.H. Dyck, Behavioural outcomes of perinatal maternal fluoxetine treatment, Neuroscience 226 (2012) 356-66.

[71] S.L. Handley, S. Mithani, Effects of alpha-adrenoceptor agonists and antagonists in a maze-exploration model of 'fear'-motivated behaviour, Naunyn. Schmiedebergs Arch. Pharmacol. 327(1) (1984) 1-5. 
[72] S. Hogg, A review of the validity and variability of the elevated plus-maze as an animal model of anxiety, Pharmacol Biochem Behav 54(1) (1996) 21-30.

[73] A.P. Cruz, F. Frei, F.G. Graeff, Ethopharmacological analysis of rat behavior on the elevated plus-maze, Pharmacol. Biochem. Behav. 49(1) (1994) 171-176.

[74] R.J. Rodgers, N.J. Johnson, Factor analysis of spatiotemporal and ethological measures in the murine elevated plus-maze test of anxiety, Pharmacol. Biochem. Behav. 52(2) (1995) 297-303.

[75] M.D. Saxe, F. Battaglia, J.W. Wang, G. Malleret, D.J. David, J.E. Monckton, A.D. Garcia, M.V. Sofroniew, E.R. Kandel, L. Santarelli, R. Hen, M.R. Drew, Ablation of hippocampal neurogenesis impairs contextual fear conditioning and synaptic plasticity in the dentate gyrus, Proceedings of the National Academy of Sciences of the United States of America 103(46) (2006) 17501-6.

[76] D.K. Kinney, K.M. Munir, D.J. Crowley, A.M. Miller, Prenatal stress and risk for autism, Neurosci Biobehav R 32(8) (2008) 1519-1532.

[77] A.S. Khashan, K.M. Abel, R. McNamee, M.G. Pedersen, R.T. Webb, P.N. Baker, L.C. Kenny, P.B. Mortensen, Higher risk of offspring schizophrenia following antenatal maternal exposure to severe adverse life events, Arch Gen Psychiatry 65(2) (2008) 14652.

[78] D. Malaspina, C. Corcoran, K.R. Kleinhaus, M.C. Perrin, S. Fennig, D. Nahon, Y. Friedlander, S. Harlap, Acute maternal stress in pregnancy and schizophrenia in offspring: a cohort prospective study, BMC Psychiatry 8 (2008) 71.

[79] L. Groenink, E.Y. Bijlsma, M.J. van Bogaert, R.S. Oosting, B. Olivier, Serotonin1 A receptor deletion does not interact with maternal separation-induced increases in startle reactivity and prepulse inhibition deficits, Psychopharmacology (Berl) 214(1) (2011) 353-65.

[80] N. Grizenko, M.E. Fortier, C. Zadorozny, G. Thakur, N. Schmitz, R. Duval, R. Joober, Maternal Stress during Pregnancy, ADHD Symptomatology in Children and Genotype: Gene-Environment Interaction, J Can Acad Child Adolesc Psychiatry 21(1) (2012) 9-15.

[81] F. Matrisciano, P. Tueting, S. Maccari, F. Nicoletti, A. Guidotti, Pharmacological Activation of Group-II Metabotropic Glutamate Receptors Corrects a Schizophrenia-Like Phenotype Induced by Prenatal Stress in Mice, Neuropsychopharmacology. 37(4) (2012) 929-938.

[82] T. Strekalova, R. Spanagel, O. Dolgov, D. Bartsch, Stress-induced hyperlocomotion as a confounding factor in anxiety and depression models in mice, Behav Pharmacol 16(3) (2005) 171-180.

[83] M.N. Hill, S.A. Kumar, S.B. Filipski, M. Iverson, K.L. Stuhr, J.M. Keith, B.F.

Cravatt, C.J. Hillard, S. Chattarji, B.S. McEwen, Disruption of fatty acid amide hydrolase activity prevents the effects of chronic stress on anxiety and amygdalar microstructure, Mol. Psychiatry 18(10) (2013) 1125-35.

[84] K.M. Heiderstadt, R.M. McLaughlin, D.C. Wright, S.E. Walker, C.E. GomezSanchez, The effect of chronic food and water restriction on open-field behaviour and serum corticosterone levels in rats, Lab Anim 34(1) (2000) 20-8.

[85] S.L. Kjaer, G. Wegener, R. Rosenberg, S.P. Lund, K.S. Hougaard, Prenatal and adult stress interplay--behavioral implications, Brain Res 1320 (2010) 106-13. 
[86] D.L. Braff, M.A. Geyer, N.R. Swerdlow, Human studies of prepulse inhibition of startle: normal subjects, patient groups, and pharmacological studies, Psychopharmacology (Berl) 156(2-3) (2001) 234-58.

[87] A. Gogos, M. van den Buuse, S. Rossell, Gender differences in prepulse inhibition (PPI) in bipolar disorder: men have reduced PPI, women have increased PPI, Int J Neuropsychopharmacol 12(9) (2009) 1249-59.

[88] K. Kleinhaus, S. Harlap, M. Perrin, O. Manor, R. Margalit-Calderon, M. Opler, Y. Friedlander, D. Malaspina, Prenatal stress and affective disorders in a population birth cohort, Bipolar Disord 15(1) (2013) 92-9.

[89] C.F. Capello, C.H. Bourke, J.C. Ritchie, Z.N. Stowe, D.J. Newport, A. Nemeroff, M.J. Owens, Serotonin transporter occupancy in rats exposed to serotonin reuptake inhibitors in utero or via breast milk, J Pharmacol Exp Ther 339(1) (2011) 275-85. [90] K.L. Bairy, S. Madhyastha, K.P. Ashok, I. Bairy, S. Malini, Developmental and behavioral consequences of prenatal fluoxetine, Pharmacology 79(1) (2007) 1-11. [91] C. Zhao, W. Deng, F.H. Gage, Mechanisms and functional implications of adult neurogenesis, Cell 132(4) (2008) 645-60.

[92] J.E. Malberg, A.J. Eisch, E.J. Nestler, R.S. Duman, Chronic antidepressant treatment increases neurogenesis in adult rat hippocampus, J Neurosci 20(24) (2000) 9104-10. [93] I. Rayen, D.L. van den Hove, J. Prickaerts, H.W. Steinbusch, J.L. Pawluski, Fluoxetine during development reverses the effects of prenatal stress on depressive-like behavior and hippocampal neurogenesis in adolescence, PLoS One 6(9) (2011) e24003. [94] A.R. Gobinath, J.L. Workman, C. Chow, S.E. Lieblich, L.A. Galea, Maternal postpartum corticosterone and fluoxetine differentially affect adult male and female offspring on anxiety-like behavior, stress reactivity, and hippocampal neurogenesis, Neuropharmacology 101 (2016) 165-78.

[95] M. Weinstock, Gender differences in the effects of prenatal stress on brain development and behaviour, Neurochem Res 32(10) (2007) 1730-40.

[96] M. Nagano, M.Y. Liu, H. Inagaki, T. Kawada, H. Suzuki, Early intervention with fluoxetine reverses abnormalities in the serotonergic system and behavior of rats exposed prenatally to dexamethasone, Neuropharmacology 63(2) (2012) 292-300. 